East African Medical Journal Vol. 77 No. 7 July 2000

SPINAL CORD COMPRESSION DUE TO TUMOURS AT KENYATTA NATIONAL HOSPITAL, NAIROBI

N.J.M. Mwang'ombe, MMed, PhD (Lond), Senior Lecturer, M.B. Ouma MBChB, MMed (Surg), Department of Surgery, College of Health Sciences, University of Nairobi, P.O. Box 19676, Nairobi, Kenya.

Request for reprints to: Dr. N.J.M. Mwang'ombe, Department of Surgery, College of Health Sciences, University of Nairobi, P.O. Box 19676, Nairobi, Kenya

\title{
SPINAL CORD COMPRESSION DUE TO TUMOURS AT KENYATTA NATIONAL HOSPITAL, NAIROBI
}

\author{
N.J.M. MWANG'OMBE and M.B. OUMA
}

\begin{abstract}
Objective: To determine the frequency of different types of tumours associated with cord compression, their mode of presentation and treatment outcome.

Design: Retrospective study.

Setting: Kenyatta National Hospital (KNH), a teaching and referral hospital in Nairobi, Kenya, from January 1985 to December 1994.

Subjects: Thirty eight patients.

Results: There were twenty one males and seventeen females with a male/female ratio of 1.3:1 and a mean age of 36.9 years. Primary spinal cord tumours were more common $(65.8 \%)$ than metastatic tumours $(34.2 \%)$. The commonest spinal cord tumour was meningioma $(23.7 \%)$ followed by neurofibroma $(15.8 \%)$. Most of the patients $(\mathbf{7 0} \%)$ did not show any clinical improvement after surgery.

Conclusion: Spinal cord tumours accounted for about $15 \%$ of all CNS tumours treated at the Kenyatta National Hospital. Most of the patients had total paralysis of the limbs at the time of presentation. Meningiomas and neurofibromas were the commonest cause of cord compression at KNH. Greater effort is needed to detect these tumours early when the signs and symptoms may be reversible following surgery.
\end{abstract}

\section{INTRODUCTION}

Surgical lesions affecting the spinal cord may be categorised into intradural and extra dural groups. Intradural lesions may be intramedullary or extramedullary. A spinal cord tumour may be primary or secondary. The origin of the primary spinal cord tumours may be neuroectodermal (gliomas), meningeal (meningioma), nerve root (schwannoma and neurofibroma) or developmental (dermoid, epidermoid and teratomas). Secondary tumours usually originate from carcinomas of the lung, breast, prostate and thyroid. Other sites of origin are lymphomas, neuroblastoma, and multiple myeloma. The incidence of spinal cord tumours is 3 to 10 per 100,000 population, $(1,2)$. The sex ratio is equal for most of the tumours $(1,2)$ except meningiomas, which are commoner in females. Most studies from the developed world report neurilemmomas as the most common intradural extramedullary tumour (30\%) followed by meningiomas (25\%). Astrocytomas and ependymomas are the most common intramedullary tumours (3). Congenital tumours such as teratoma, dermoids and epidermoid tumours, although rare, are common in children. A high percentage (nearly $90 \%$ ) of all intradural spinal cord tumours are benign and the clinical manifestations are due to cord compression (3). Rapid compression (3) is less likely to be followed by recovery than compression which develops over a course of many months or years.

\section{MATERIALS AND METHODS}

All patients with spinal cord tumours treated at the Kenyatta National Hospital between January 1985 and December 1994 were included in this study retrospectively. Details of the patients were obtained from the Records Department, Radiology Department and Hospital Theatre records. The records of these patients were reviewed with respect to age and sex distribution, clinical presentation, investigations done, time period between onset of illness and admission to hospital, level of lesion, treatment offered and outcome following treatment.

\section{RESULTS}

Thirty eight patients with spinal cord tumours underwent surgery at the Kenyatta National Hospital $(\mathrm{KNH})$ between January 1985 and December 1994. Twenty one were males and seventeen were females giving male/ female ratio of 1.3:1. Their ages ranged from six years to 70 years with an average age of 33.6 years for males and 40.2 years for females. The frequency peaked at $30-39$ years for males and 40 - 49 years for females (Figure 1). The 
common presenting complaints were sensory loss (89\%), limb weakness (63\%), paraesthesia (42\%), back pain (37\%) and sphincteric disturbances $(23 \%)$ (Table 1). Two patients did not have any disability at the time of presentation at the hospital, five were able to walk with support (mild disability), twenty (52.6\%) had some degree of limb movements present but were unable to walk even with support and eleven (29\%) had total paralysis.

Figure 1

Age distribution

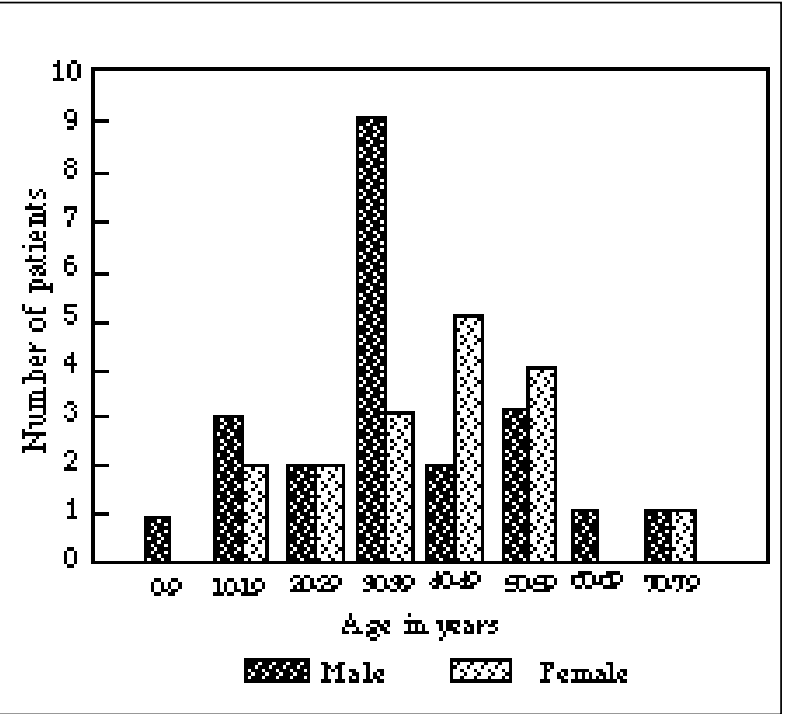

Table 1

Presenting symptoms in patients with spinal cord tumours

\begin{tabular}{lcc}
\hline Symptom & Number of patients & Frequency (\%) \\
\hline Sensory loss & 34 & 89 \\
Weakness of extremities & 24 & 63 \\
Paraesthesia & 16 & 42 \\
Back pain & 14 & 37 \\
Incontinence (stool/urine) & 6 & 23 \\
\hline
\end{tabular}

Eighty per cent of the patients were therefore not able to walk at all (even with support) at the time of presentation to hospital (Table 2). Eighteen patients (47.4\%) had normal plain $\mathrm{x}$-ray of the spine. Common abnormal findings were osteo arthritic changes, erosion and collapse of vertebral bodies. Partial block after myelography was reported in 12 patients $(32 \%)$ and total block in $26(68 \%)$. Computerised tomography $(\mathrm{CT})$ scan was done in eight patients and was positively diagnostic of cord tumour in all. Analysis of cerebrospinal fluid was done in eleven patients and seven of these were normal, while protein levels were raised in four. Six patients presented within three months from the time of onset of symptoms, sixteen patients came to hospital between the fourth and the seventh month, five patients between the eighth and eleventh month and eleven patients after more than eleven months (Figure 2). The commonest site for spinal cord tumours was thoracic (47\%) followed by cervical (26\%) and lumbar (7\%). Twenty per cent of the lesions were found to involve multiple sites. Intradural lesions were more common (55.3\%) than extradural lesions (44.7\%). Fifty seven per cent of the intradural tumours were extramedullary, $33 \%$ were intramedullary and ten per cent involved the caudaequina.

Figure 2

Duration between onset of symptoms and surgery

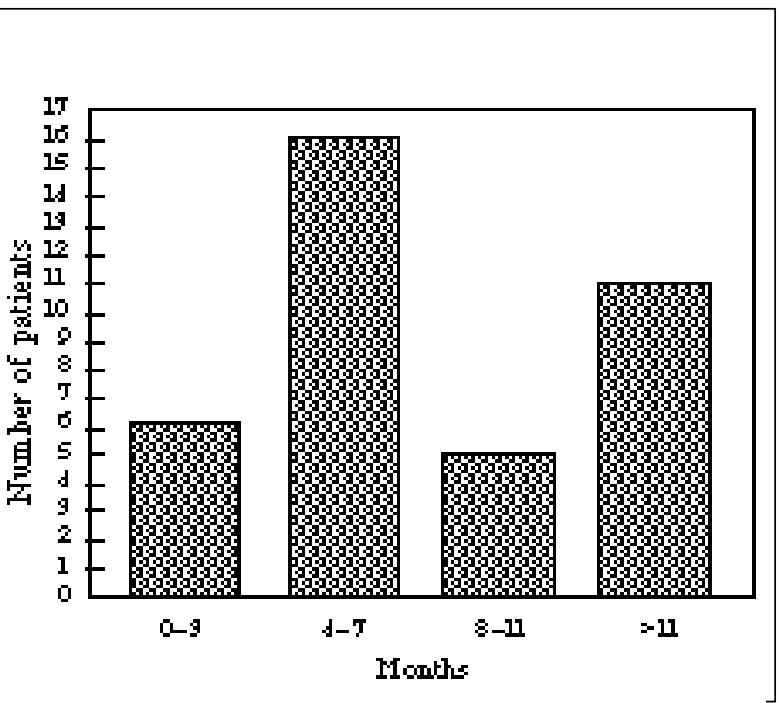

Table 2

Degree of disability at presentation in patients with spinal cord tumours

\begin{tabular}{lcc}
\hline $\begin{array}{l}\text { Degree of } \\
\text { disability }\end{array}$ & Number of patients & Frequency (\%) \\
\hline None & 2 & 5.2 \\
Mild (able to walk with support) & 5 & 13.2 \\
$\begin{array}{l}\text { Moderate (limb movement } \\
\text { present, unable to walk) }\end{array}$ & 20 & 52.6 \\
Severe (total paralysis) & 11 & 29 \\
\hline
\end{tabular}

Figure 3

Time duration (months) between admission and surgery for patients with spinal cord tumours

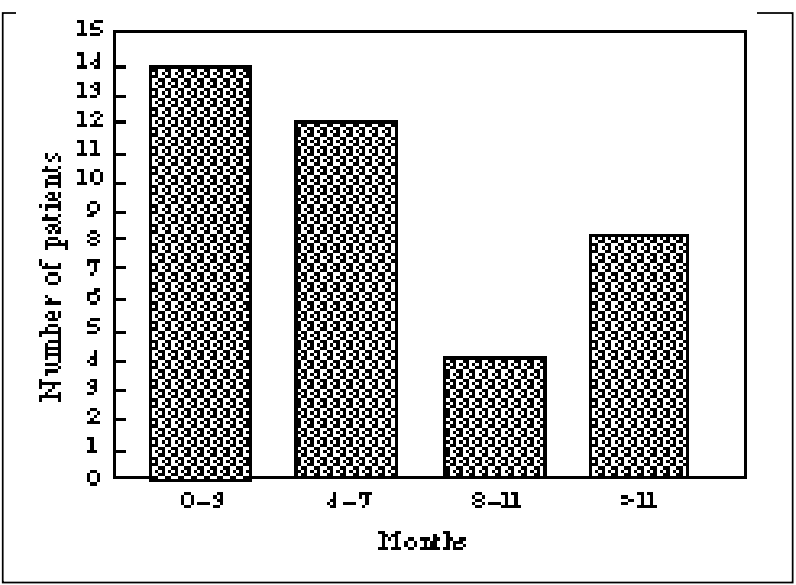


Twenty five patients were managed by surgery alone $(65.7 \%)$, seven had surgery and radiotherapy (18.4\%), one had surgery and chemotherapy $(2.6 \%)$. Five patients with malignant metastases did not undergo surgery, because it was thought surgery would be of no benefit. Fourteen patients underwent surgery within three months from the time of admission into hospital, twelve patients between four and seven months, eight patients between eight and eleven months and eight patients after eleven months (Figure 3). Eleven patients (29\%) had no significant improvement in their condition following surgery. Five patients (13\%) had a full recovery and were able to walk without support. Seven patients (17.4\%) had partial recovery and could walk with support or with the aid of crutches.

\section{DISCUSSION}

The incidence of spinal cord tumour has been reported to vary between 3 and 10 per 100,000 population in the developed world $(1,2)$. A previous study at the Kenyatta National Hospital which reviewed cases of spinal cord tumours seen over a five year period, from January 1981 to December 1984, reported a frequency of six cases per year for both primary and secondary tumours (4). In total 1,381 patients underwent surgery in the Neurosurgical Unit during that period giving an average of 276 patients per year. In this study, an average of four cases were seen per year over a ten year period and 2564 patients underwent surgery in the unit during that period, an average of 256 patients per year. The mean age at presentation observed in this study was 36.4 years and there was only one patient below the age of nine years. Fornari reported a mean age of 37 years in his patients with spinal cord tumours and only nine of his patients (11\%) were children(5). Most of the patients presented with sensory loss, weakness and back pain(6). These findings are similar to those reported in an earlier study done at the Kenyatta National Hospital (4). However, other studies have reported back pain to be the most common presenting symptom, being observed in $68 \%$ of patients (6). A study done in Kampala, Uganda, found urinary incontinence to be the most frequent presenting complaint (seven out of 23 patients) followed by paresis (six patients) and backache, five patients(7).

Thirty seven per cent of patients seen in this study presented to hospital within three months of onset of symptoms and $68 \%$ within seven months. Meningiomas and neurofibromas were seen in nearly forty per cent of all patients with spinal cord tumours treated during that period. These are slow growing tumours. It is therefore more likely that late presentation was associated with the severe neurological deficits obsessed in patients with spinal cord tumours seen in this study. The commonest sites of tumour location were thoracic spine (47\%) followed by cervical spine $(31 \%)$. Similar findings were reported by Fornari (thoracic 42\% and cervical 36\%) (5) and in an earlier study done at the Kenyatta National Hospital (thoracic 37\%, lumbar $10 \%$ and cervical spine 6\%) (4).

In this study, meningioma was the commonest primary spinal cord tumour $(36 \%)$ followed by neurofibroma
(24\%). A previous study done at Kenyatta National Hospital in 1985 found meningiomas to be two times as common as neurofibromas (4). However, studies done elsewhere in the developed world have found neurofibroma to be more common $(8,9)$. This study confirms meningioma as the commonest spinal cord tumour in Kenya Africans far surpassing neurofibroma.

In developed countries, metastatic tumours of the spinal cord are more common than primary tumours. In this study, metastases made up $34 \%$ of all tumours of the spinal cord. A previous study done in the same hospital in 1985 found that metastases accounted for $39 \%$ of all spinal cord tumours(4). The high frequency of metastatic spinal cord tumours in developed countries is usually attributed to the long life expectancy rates seen in those countries which are associated with development of more malignant tumours in their population. The life expectancy rates are still low in the developing world and people may not be living long enough to develop excessive metastatic tumours.

This study highlights two observations which are commonly seen in patients undergoing treatment for neurological illness in the developing world. These are late presentation into hospital and a significant delay while in hospital before definitive surgery. The late presentation is usually associated with the fact that patients commonly go for traditional forms of treatment before seeking conventional treatment. The delay while in hospital is associated with shortage of specialists and hospital resources. This situation will only improve following campaigns to increase public awareness on the relevance of seeking early medical treatment and after improvement of primary health care facilities and the referral system. Although the number of specialists within the country is now higher than it was before, greater emphasis will need to be put on ways and means of utilising these specialists more efficiently through provision of necessary auxillary resources.

\section{ACKNOWLEDGEMENTS}

To the Director, Kenyatta National Hospital and the Research and Ethics Committee, Kenyatta National Hospital, for permission to carry out this study and publish the findings.

\section{REFERENCES}

1. Austin, G. The spinal cord; basic aspects and surgical considerations $2^{\text {nd }}$ Ed. Springfield, Illinois, Charles C Thomas 1972 PP 281 - 283.

2. Connolly, E.S. spinal cord tumour in adults. Youmans, J.R. (Ed) Neurological Surgery 2nd Ed. Philadelphia, Saunders 1982 PP 1849.

3. Wilkins, R.H., Rengachary, S.S. Neurosurgery Vol. 1. Newyork. McGrowHill, 1985. PP 1049.

4. Randal, J.H. Compressive lesions of the spinal cord in Kenya, as seen and treated in the neurosurgical department in Kenyatta National Hospital, January 1981 to December 1984. MMed thesis. 1985. University of Nairobi.

5. Fornari, M. Microsurgical treatment of spinal cord tumours. Acta. neuro. chir-suppl-wien. 1988; 43: 3 - 8.

6. Bach, F. Metastatic spinal cord compression. Occurrence, symptoms, clinical presentation and prognosis in 398 patients with spinal cord compression. Acta-Neurochir-wien. 1996; 107: 37-43.

7. Murphy, N.B. Hardikar, S.M. Non traumatic paraplegia in Uganda. A review of 23 cases with spinal canal obstruction. East Afr. Med. J. 1968; 45:177 -189.

8. Harris, B. Spinal cord compression. Brit. Med. J. 1970;1: (011 -614)11 (673 - 676)

9. Kernohan, J.W., Syre, G.P. Tumours of central nervous system in Armed Forces Institute of Pathology Series 10, Fose, 35 and 37,1952. 